\title{
DEVELOPMENT OF A CONCEPTUAL FRAMEWORK OF HOLISTIC RISK ASSESSMENT - Landfill as a particular type of contaminated land
}

T. E. Butt ${ }^{* 1}$; A. A. Javadi' $;$ M. A. Nunns ${ }^{3}$; C. D. Beal ${ }^{4}$

${ }^{* 1}$ School of Architecture, Built \& Natural Environments (SABNE); Faculty of Architecture, Computing \& Engineering (FACE); Swansea Metropolitan; University of Wales Trinity Saint David (UWTSD). Mount Pleasant Campus; Swansea. Post Code: SA1 6ED. Wales, UK.

Tel: ++ 44 (0) 7817139170; Email: t.e.butt@ outlook.com

${ }^{2}$ Department of Engineering, College of Engineering, Mathematics \& Physical Sciences (CEMPS), University of Exeter, Harrison Building, North Park Road, Exeter. Post Code: EX4 4QF. England, UK.

${ }^{3}$ Environment Agency, Bromholme Lane, Brampton, Huntingdon. Post Code: PE28 4NE, England, UK.

${ }^{4}$ Smart Water Research Centre (SWRC) and School of Engineering, Griffith University, Southport, Queensland, 4222, Australia

\begin{abstract}
Landfills can be regarded as a particular type of contaminated land that has a potential to directly and indirectly pollute all of the four main spheres of the environment which are the lithosphere, atmosphere, hydrosphere and eventually adversely impact the biosphere. Therefore, environmental risk assessment of a landfill has to be more integrated and holistic by virtue of its nature of being a multidimensional pollutant source. Despite this, although various risk assessment approaches have been adopted for landfill waste disposal sites, there are still wide-ranging knowledge gaps and limitations which need to be addressed. One important knowledge gap and limitation of current risk assessment approaches is the inability to fully identify, categorise and aggregate all individual risks from all combinations of hazards, pathways and targets/receptors (e.g. water, air, soil and biota) in connection to a certain landfill leachate and yet at any stage of the landfill cycle. So such an approach is required that could not only integrate all possible characteristics of varying scenarios but also contain the ability to establish an overall risk picture, irrespective of the lifecycle stage of the landfill (e.g. planning stage/pre-operation, in-operation or post-operation/closed). One such
\end{abstract}


approach to address the wide-breadth of landfill impact risks is by developing a more holistic risk assessment methodology, whose conceptual framework is presented in this paper for landfill leachate in a whole-system format. This conceptual framework does not only draw together various constituting factors and sub-factors of risk assessment in a logical sequence and categorical order, but also indicates the "what, why, when and how" outputs of and inputs to these factors and subfactors can be useful. The framework is designed to identify and quantify a range of risks associated with all stages of the landfill lifecycle, and yet in a more streamlined, logical, categorical and integrated format, offering a more standardised and unified whole-system approach.

Keywords: risk assessment; risk analysis; conceptual framework; contaminated land; waste disposal sites; landfill leachate.

\subsection{INTRODUCTION}

\subsection{Background}

As with other types of contaminated land, risk assessment is increasingly being applied to landfill sites, at the planning, operational and/or completion stages $(1,2,3,4)$. Risk analysis is also being supported by environmental legislation in various countries (5) thus making it a mandatory part of the landfill design process. For example, a risk assessment (RA) requirement for the protection of groundwater from landfill leachate has been a legislative requirement in the UK since 1st May 1994, through Regulation 15 of the Waste Management Licensing Regulations, 1994 (6, 7). Risk assessment is a vital tool for determining the level of environmental risk control, which subsequently dictates the level of risk reduction - the ultimate aim of a risk assessment procedure. Thus, the degree of effectiveness of the risk control and risk reduction is highly dependent on the level of accuracy and detail of information derived from the risk assessment.

An exhaustive review of risk analysis approaches carried out by Butt et al (5) highlighted that a comprehensive, robust and sound framework of risk assessment in a holistic manner, with a range of features does not exist. Examples of such features are listed below. Butt et al $(5,26,35)$ also explained why a holistic risk assessment approach can be more useful than traditional tools. For instance, the Water Framework Directive (27) is being transposed and implemented in the UK and the other European Union member states. This Directive includes new requirements for the protection and restoration not only of ground waters but also surface waters and dependent ecological systems (1). Similarly, the Landfill Directive and Regulations take it beyond surface and 
ground waters only, and include air, soil, global environment, greenhouse gases, and human health $(28,29,30,31,32,33)$. Another directive, generally referred to as Habitat Directive (34), introduces a legal obligation to combat hazards in order to guard and enhance natural habitats and wild fauna and flora. On the basis of these key pieces of environmental legislation, which are increasingly becoming more holistic, it can be concluded that a sound holistic approach towards risk assessment is not only appropriate, but may well be mandated in the near future. Despite this, current guidance notes and approaches (such as chemical prioritisation) regarding risk assessments do not offer a holistic framework specifically for landfills and do not appear to have $(5,8,18,26$, $35,37,38,39,40,41)$ :

- systematic features to help establish an overall risk posed by a given landfill by aggregating all the individual risks for each combination of all the hazards, pathways and targets / receptors;

- structured characteristics that could clearly distinguish between toxic, non-toxic, carcinogenic and non-carcinogenic hazards; and accordingly workout either hazard indices or risks or both;

- various types of landfill systems and their surroundings encompassed in the framework;

- taken into account all possible characteristics of landfills in terms of risks and quantification of risks posed by landfills;

- included procedures for individual constituents of RA (e.g. baseline study, hazard identification and categorisation, hazard concentration assessment, exposure assessment with exposure quantification; pollutant migration analysis and likelihood or probability of a target / receptor to be effectively hit by the hazard.)

- included other features and scenarios that render RA more comprehensive such as significance assessment, uncertainty assessment, risk measurement for most likely and worst case scenarios, etc.

\subsection{Aim and Scope}

One of the most important knowledge limitations identified in the literature is the absence of a sequential / stage-by-stage, categorical and quantitative methodology to perform risk analysis in a holistic fashion for a contaminated land in general and for landfill leachates in particular. Where various disciplines (such as hydrology, geology, hydrogeology, topography, toxicology, statistics, etc.) are explicitly integrated in a multi-, inter-, cross- and trans-disciplinary manner and yet able to yield aggregated overall risk value in each of these three themes separately: toxicity, 
carcinogenicity and non-carcinogenicity $(5,37)$. The main aim of this paper is to present a conceptual model, in the form of a framework of a holistic risk assessment methodology in which all factors and sub-factors of the risk assessment are categorically and sequentially drawn together and the afore-listed absent features (Section 1.1) are appropriately integrated. In pursuit of this, following on from the authors previous literature review papers $(5,26,35)$ in which knowledge gaps were identified in detail; the scope of this paper is to bridge those identified knowledge gaps by building new and innovative knowledge blocks. Yet, also more systematically assemble together existing knowledge blocks from current risk assessment approaches and eventually demonstrate a conceptual framework of an exhaustively more holistic risk assessment approach. Innovative features of this conceptual framework are indicated throughout the paper, where appropriate.

The focus of the paper is not to present detailed computer code and calculations, but to present and discuss a conceptual framework of the holistic risk assessment methodology, which with further research may be transformed into a computer-aided tool. Thus, the use of the word 'module' in the paper is not in the sense of a computer code but merely due to the modular approach that the paper employs. Similarly, the terms 'assessment' and 'analysis' in connection to risk are used interchangeably in the paper for these are implied in different parts of the world in the same sense. For instance, in the USA it is generally referred to as Risk Analysis and in the UK, Risk Assessment. A notation table (in association with Figure 1) is provided towards the end of the paper which can well be used as a brief glossary for the terminologies used in the paper. These terminologies, however, are defined and described as and when they come up in the text description. However, with in the scope of this paper, the term 'holistic' implies an overall umbrella encompassing or encapsulating all aspects and factors of risk assessment only of landfill leachate from the start to the end.

Although the focus of the paper is to cover the entirety of the risk analysis methodology in the form of a fundamental framework, the study does not engage in-depth detail of factors and sub-factors of the methodology due to the need for brevity. Also, in order to put Risk Assessment (RA) in a broader perspective of decision-making process, the relationships between Risk Management (RM), Hazard Assessment (HA), and Risk Estimation (R Esti) are also presented along with their respective definitions and implications in the later sections of the paper, where appropriate.

The authors consider landfills to be a type of contaminated land amongst other such examples including fuel stations, military sites, mine pit lakes, tailings, spoils piles, deep geological burial of radioactive substances, and industrial sites. Although the focus of the paper is specifically on 
landfills, the holistic framework may be adapted for other point-source contaminant sources such as mentioned above. However, landfill risk assessments in comparison with other contaminated land types may still exhibit some specific differences in terms of e.g. leachate management including onsite and / or off-site treatment as a waste water; landfill engineering; waste treatment and management on site such as compaction; waste types like industrial, hazardous, commercial, domestic, municipal, special wastes; etc. in instances such as these, the model may not be applicable to other contaminated land types.

\subsection{THE DEVELOPMENT STRATEGY}

With reference to Figure 1, the development strategy for building the holistic framework is based on these elements:

1. The initial step is to identify all constituents / modules and sub-constituents / sub-modules of risk assessments at various tiers. In this paper the word module is used in the context of a constituent or factor not in any other sense such as computer code. These components and subcomponents come from existing knowledge blocks from current risk assessment approaches. And as for the knowledge gaps, which were identified in the authors previous publications (5, 26, 35), new building blocks of knowledge are created.

2. All these constituents and sub-constituents are gathered under one overall umbrella and categorised into groups in a logical order.

3. All these groups of constituents and sub-constituents are assembled in a logical sequence under the umbrella.

4. The feature of quantification is introduced in all appropriate parameters in order to render the RA methodology quantitative. However, it should be noted that all parameters or items in a RA process may not necessarily always be quantified or quantifiable but only based on judgement or non-measured data. This is where the Uncertainty Assessment constituent of the RA (discussed later in Section 3.2.3) becomes a lot more useful and important.

5. The development strategy also takes into accounts, which constituents are common to or overarch other constituents of the RA framework. Examples of such common constituents are Significance Assessment and Uncertainty Assessment.

6. In the development of the framework, it is also specially appreciated that outputs of which constituents and sub-constituents are inputs to which other constituents and sub-constituents. This way mutual relationships between constituents and sub-constituents are established. 
7. Such mutual relationships amongst constituents and sub-constituents can also assist traceability and transparency. However, all constituents and sub-constituents are not described to full scale but only to an appropriate extent due to brevity.

8. Brief examples are employed in these components and sub-components of the framework where appropriate, in order to more clearly describe their effectiveness in specific scenarios.

\subsection{THE DEVELOPMENT OF THE CONCEPTUAL FRAMEWORK OF THE HOLISTIC RISK ASSESSMENT}

Risk Management (RM) consists of two main factors i.e. the Risk Assessment / Analysis (RA) and the Risk Reduction (RR) (see Figure 1). RA is further divided into two parts Hazard Assessment (HA) and Risk Estimation (R Esti). The output of HA is an input to R Esti and this is how the HA provides a foundation for the RA (see Figure 2). The better and stronger this foundation is, the more effective and efficient the risk assessment and consequently the risk management will be. In a given RA, the HA process predominantly involves identification, categorisation and significance analysis of all potential hazards, pathways and targets / receptors based upon preliminary investigation or baseline study. Whereas the R Esti is regarding the consideration of the likelihood of a hazard hitting a target / receptor, or estimating probability of happening of an undesired event. The process of using the outcome of a risk analysis to investigate risk control options, and actions taken to mitigate hazards and unwanted consequences is called Risk Reduction which thereby accomplishes the whole RM exercise. This paper is mainly focused on RA and not RR. Therefore, the relationship between modules and sub-modules of HA and R Esti, which together form a total RA system, are to be discussed in the following sections of this paper. In conjunction with Figure 2, however, Figure 3 depicts that HA is subset to RA is subset to RM.

Keeping in view the aforesaid elements of the development strategy (Section 2.0), the HA is divided into four sub-parts as follows:

1. Baseline Study (BS),

2. Hazard Identification and Categorisation (H Iden),

3. Exposure Assessment (Ex A) and

4. Concentration Assessment (CA) of hazards

The R Esti is also divided into four sub-parts, which are: 
1. Migration Assessment (Migra A),

2. Significance Assessment (Sig A),

3. Uncertainty Assessment (UA) and

4. Risk Characterisation (R Charac).

These eight sub-parts of HA and R Esti are elaborated further in the form of a conceptual framework of the holistic RA system as follows:

\subsection{The Hazard Assessment (HA)}

\subsubsection{Baseline Study (BS)}

The Baseline Study is defined as the most preliminary step of a hazard assessment as well as risk analysis in which all basic information / data is gathered, organised and analysed (35). Hazard and risk assessment process is based on the baseline study. For a contaminated land scenario such as landfill leachates, the BS has to take account of a wide range of information and subjects. The information can be categorised into eight modules as follows: 1) Geology, 2) Hydrology, 3) Hydrogeology, 4) Topography, 5) Meteorology, 6) Geography, 7) Site Management and 8) Human Influences (8). Figure 1 gives a representation of the eight modules and their respective submodules. In this study, the eight modules of the BS are only described very briefly to exhibit an overall picture of how the BS and the eight modules have been developed in a holistic manner for the RA framework. There may be some overlaps between the BS modules and sub-modules depending on site-specific characteristics of a given scenario because science subjects overlap and do not have very strict and solid boundaries of knowledge. For instance, precipitation is a common sub-module to hydrology and meteorology modules of the BS (Figure 1). In such cases, it is optional for the risk assessor to cover precipitation either under hydrology or meteorology.

In the geology module, the lithosphere is divided into three main layers as follows: Top Soil, Drift and Rock. In this module, a risk assessor will establish relevant properties for the three layers e.g. minerals, porosity, fissures, and other geological properties. The hydrology module is constituted by two main sub-modules: 'Atmosphere Waters' and 'Lithosphere Waters' (Figure 1). The former addresses waters in the atmosphere, such as precipitation (rain, snow and sleet), evapo-transpiration and interception. The latter covers sub-modules including runoff, infiltration, percolation, groundwater ingress, and water courses. The hydrogeology is a science subject that exists in the overlapping area between geology and hydrology modules of the BS. Thus this module is bound to 
have a few common areas between geology and hydrology modules e.g. groundwater ingress. The hydrogeology module is divided into three main groups including hydrogeological zones (vadoze, phreatic and perched zones), ingress and hydrogeological properties e.g. hydraulic gradient, permeability, groundwater flow and direction, etc.

Topography generally covers landforms / ground surface contours. From the RA framework perspective, this paper widens boundaries of the topography module to include two more submodules: natural environment and built environment. In the landforms sub-module, a hazard assessor needs to identify slopes of the ground surface in the direction of and away from the site being assessed. These slopes will assist in estimating water runoffs in the direction of and away from the site for the hydrology module above. This is an example of relationships between submodules of the RA process. The natural environment sub-module is useful in identifying natural species, including the location of plant life, wild life, and aquatic life (along with their respective nature and sizes) in the region with reference to the location of a given site being assessed. The nonliving (non-biotic), such as surface water courses or groundwater, have already been addressed in the hydrology module of the BS. Like the natural environment, in the built environment submodule, items such as buildings, houses / residential areas, commercial areas, and their sizes and nature can be mentioned. The information from the natural and built environment sub-modules will be an input to the targets / receptors identification, which is one of the sub-modules of the Exposure Assessment (Ex A) module discussed later.

The meteorology module comprises entities such as wind speed and direction, degree of cloudiness and sun, air pressure, wet and dry bulb temperatures, humidity, precipitation and others. All such parameters vary temporally and spatially. For a more accurate RA, statistical description of the parameters may be required. Similarly, the geography module accounts for parameters such as the geographical location of a given site (like latitudes, and longitudes). Other relevant geographical properties (such as tropical) can be considered for a given site under this module. The site management module covers a wide range of issues related to a given site itself. These include, site history, site type, site location, site map and layout, site engineering (design and construction), environmental monitoring, waste management practices and other site operations such as waste handling, documentation, waste analysis, waste types land-filled, amounts of wastes, night cover, weigh bridge, wind screen and equipment management. In the human influence module a risk assessor can identify past, present and future potential human influences in the region around the site, which could be affected by the existence of the contamination in the site. For instance, will 
there be any potential for quarrying, buildings construction, water abstractions and other developments in future or are such human activities already underway?

One of the major issues with risk assessments is timeframe, for instance, how long would be taken from the time of placement of material to the time when, e.g. groundwater pollutants' concentrations may be highest at the point of exposure? In some cases, this time duration could be tens of years (or even less) and sometimes as many as hundreds of years depending on characteristics of a given scenario e.g. type of waste, geological materials nature, hydrogeological settings, or even the nature of the pollutant and / or receptor, etc. $(1,2,910)$. This reinforces the idea that a risk analysis should be performed for different 'age scenarios' of a given site being assessed. For instance, durations of 10, 30, 50 and specially 70 years which represents an average human generation length, should be considered in carcinogenic risk assessments - a toxicological scenario $(11,12)$, and even hundreds of years to cater for the future generations as the 'Sustainable Development' concept advocates. In order to account for various scenarios due to spatial and temporal variations in landfill systems a number of iterations of the risk analysis process may be needed. This must be noted that, for instance, due to a certain geological or hydro-geological setting of a given site, the peak dose time may run out a generation period and strike in future of another generation era. In such a case, different ages or time-bands should be applied and the peak dose or the highest dose among all the risk assessment iterations should be considered. This aspect is not discussed any further due to brevity.

\subsubsection{Hazard Identification and Categorisation (H Iden)}

From the perspective of risk analysis the definition of the term hazard has been stretched beyond being a substance only. It is defined as follows: a hazard means anything such as a substance, a property, a process or even a layout / setting that may cause harm(s) or has a potential to cause $\operatorname{harm}(\mathrm{s})(13,14)$.

The Hazard Identification and Categorisation (H Iden) is the second stage of the RA process, which follows the first phase, the Baseline Study (see Figure 1). In this stage, all potential hazards of leachate, either pollutants (e.g. lead, mercury, phenols or cresols, toluene, xylene; plus any new emerging pollutants as the toxicology and other associated sciences grow) or properties (e.g. pH, biological oxygen demand (BOD), chemical oxygen demand (COD)), are identified and categorised into groups for a more comprehensive, effective and categorical RA. In the light of the definition of the term hazard given above, four modules comprising 1) Quantity Hazard, 2) Quality Hazard 
(pollutant or property), 3) Process and / or layout hazard and 4) Harms are defined and discussed below:

\subsubsection{H Iden Quantity module}

In the $\mathrm{H}$ Iden Quantity module, a risk assessor is expected to estimate the quantity of leachate in a given site. The quantity of leachate itself is deemed as a hazard in the $\mathrm{H}$ Iden. The estimation of leachate quantity can be carried out by using an empirical method such as mass balance or water budget approach. This will involve factors including, precipitation, interception, evapotranspiration, run-off, groundwater ingress, and liquid wastes, if any. The information on these factors will mostly come from the hydrology module of the BS. A risk assessor may not have to literally carry out an exercise of leachate quantification every time the framework is being used as this information may already exist and may be held by a legitimate organisation, for instance, the Environment Agency in the United Kingdom and Environmental Protection Agency in the United States.

\subsubsection{H Iden Quality module}

After leachate quantity has been worked out, a risk assessor can switch to the H Iden Quality module of the RA process. In this module, hazards posed by leachate in terms of its qualities are characterised. This module is further categorised into two sub-modules namely, pollutants and properties. The former comprises the hazardous substances (such as Cobalt, Barium), which may exist in a given leachate. The latter, unlike substances existing in leachate in physical form, deals with the properties of leachate e.g. BOD (biochemical oxygen demand), $\mathrm{pH}$ value (i.e. balance of acidity and basicity / alkalinity), age of leachate, hardness. In the H Iden Quality module, there is a facility for a risk assessor to categorise leachate qualities into groups of toxic, non-toxic or both. If the toxic category is chosen, then it can be further classified into carcinogenic, non-carcinogenic, or both categories (see Figure 1).

\subsubsection{H Iden Process and / or Layout Hazard module}

In this module, a risk assessor is expected to consider items such as groundwater level fluctuation, heavy rain, liners and capping failure or no liners and capping used, fissures in bedrock, high porosity of bedrock. All such items are to be considered in the context of process and / or layout hazards posing risk or adding more to the degree of overall risk. Necessary information on all such 
items will come from the eight modules of the BS. In some cases it may be difficult to differentiate between 'Process' and 'Layout'. For instance, the higher the groundwater level, the more the hazard and risk and this could be seen as a hydro-geological layout hazard. But at the same time, this also depends on the fluctuation of the groundwater level over time, which is a hydro-geological phenomenon or process affecting the degree of the environmental hazard and risk. Similarly, application of liners to a given landfill or no liners is a matter of layout. However, their failure over a time period may be described as a process. These examples explain why this module deals with both the process and layout.

\subsubsection{H Iden Harms module}

The last and fourth module of $\mathrm{H}$ Iden module is Harms, which implies damage, loss, hurt, or injury. This module is not specifically about hazards. It specifies the potential harms that could come from the hazards that would have already been identified in the above three modules of the $\mathrm{H}$ Iden for a given waste disposal site. That is why this module is common to all the above three modules as shown in Figure 1. Also, it is the nature of a harm that assists in categorising a given leachate hazard. For instance, if the harm from a hazard such as polychlorinated biphenyls (PCBs) causes cancer then PCBs would be deemed as a carcinogenic hazard.

\subsubsection{Exposure Assessment (Ex A)}

The exposure assessment process is one of the fundamental stages of RA in which all possible hazards at the pollutant source, pathways and environmental targets / receptors are identified and categorised. In addition, for a risk analysis to be quantitative, exposures of the identified targets / receptors to the identified hazards through the identified pathways are to be measured or quantified. The Ex $\mathrm{A}$ is seen as one of the most significant, important and effective factors of hazard and risk assessment, as the success of the latter is based on the former because risk is not just a matter of hazard, pathway and target / receptor. The degree of exposure also plays a key role for a risk to exist. For example, if a hazard and a target / receptor exist, and the pathway has been manipulated in such a way that there is no exposure (i.e. exposure is zero) then the target / receptor faces no risk. Furthermore, in order to quantify risk in a risk assessment process, exposure of targets / receptors to hazards has to be quantified as well. From the quantification point of view, this is another important link between the RA and Ex A. 
The Ex A section of the framework is divided into four main modules as follows: 1) Source Identification and Categorisation (Sorc Iden), 2) Pathway Identification and Categorisation (P Iden), 3) Target (or Receptor) Identification and Categorisation (T Iden) and 4) Exposure Quantification (Ex Quan). These modules shown in Figure 1 and are explained below.

\subsubsection{Source Identification and Categorisation module (Sorc Iden)}

In Sorc Iden module, a given contaminated site or landfill is identified as a pollutant source. This module also allows the identification and categorisation of a given site into different portions in a number of ways. For instance, which parts of the given waste disposal site are active, post closed and in design / planning stage; which cells have similar dimensions. A risk assessor can also identify, geometrically, an equivalent and effective centre point in a given site body. The distances to the targets / receptors and exposure media can be measured from this centre point, as a site generally does not have regular dimensions.

\subsubsection{Pathway Identification and Categorisation module (P Iden)}

In the P Iden module a risk assessor identifies all likely / possible pathways connecting a given site with likely targets / receptors in a given scenario. The main focus of this module is the identification of all links between the two ends of each pathway, i.e. between a given site (the pollutant source) and a considered target / receptor. Since the given site (i.e. source) and targets / receptors are to be dealt within their respective modules (Sorc Iden and $\mathrm{T}$ Iden, respectively) therefore they are not to be the main focus in the P Iden module. However, Conceptual Exposure Pathway (CEP) method can be used to make P Iden module more comprehensive (15).

\subsubsection{Receptor or Target Identification and Categorisation module (T Iden)}

In the $\mathrm{T}$ Iden module, a risk assessor categorically specifies all likely environmental species that could be affected by hazards in a given contaminated site. These will not be only humans, but other potential terrestrial and aquatic flora and fauna. Also, targets / receptors may not necessarily be only living (biotic), but could also be non-living (non-biotic) such as atmosphere, lithosphere / land, hydrosphere, buildings, structures. These targets / receptors could be either off-site or on-site.

The fundamental information obtained from these modules for a given site will come from the BS where a risk assessor already would have gathered necessary information. For instance, topography 
module of BS can assist in the identification of potential environmental targets / receptors; geology and hydrogeology modules can be helpful in establishing pathways.

\subsubsection{Exposure Quantification module (Ex Quan)}

In the fourth and last module entitled Ex Quan, there are a number of ways to quantify exposure, for instance exposure equations (examples of which are given below as Eq 1 and Eq 2). These depend upon quality, nature, type and size of data and information available. The quantification of exposure also depends on the nature of an individual target / receptor, hazard and pathway and their combinations. While such details are not covered within the scope of this paper, further information can be found in various literatures such as 11,12, 16, and 17. The exposure routes in the Ex Quan module, through which hazards could enter a given target / receptor boundary, have been divided into four types. These are ingestion, dermal contact, inhalation and 'others if any' (Figure 1).

For living (or biotic) targets / receptors, like humans, there are three possible exposure routes which are: ingestion, dermal contact and inhalation. Ingestion includes drinking and / or eating. Dermal contact includes activities like, taking a shower, bathing and swimming. The exposure route of inhalation deals with breathing in some polluted air, gas or vapours. The fourth route, entitled 'others if any', has been introduced in order to provide a facility to the risk assessor to account for exposure routes other than the three indicated earlier and is specifically useful in cases of non-biotic targets / receptors. For example, an aquifer polluted with leachate could lead to a situation where a river is seen as a target / receptor. Thus, the entrance of the leachate hazards into the river via the aquifer will fall under the category of 'others if any' type exposure route. On the top of non-biotic scenarios, this exposure route may also be used in unusual biotic scenarios e.g. an injection doze to a patient, etc. This also indicates the flexibility of the RA framework in terms of variety of scenarios of environmental targets / receptors it can accommodate, and yet via wide-ranging exposure routes. If a given hazard affects a specific organ of a target / receptor (such as a human stomach) via a specific exposure route (like ingestion), then other exposure routes can be safely neglected for such a case. If the values for exposure routes other than ingestion are still considered in such a case, then this will, however, add on the degree of 'conservativeness' in measuring exposures and consequently risks.

Statistical descriptions such as maximum, mean, mode, most likely and minimum can be employed in exposure quantification (as explained with exemplary exposure equations below). These statistical descriptions would, eventually, assist the quantification of both most likely and worst 
case scenarios of risk. For instance, maximum exposure can correspond to worst case scenario of risk and mean or mode (which ever is measurable) to most likely scenario. This is elaborated further in Section 3.2.4.1 (immediately below Eq 6). Since the modules Sorc Iden, P Iden and T Iden are descriptive (or non-numeric) in nature (as explained above), these statistical descriptions are not applicable to them. In this sense, these three modules contrast with the Ex Quan module, which is numerical and objective in nature.

$$
\text { Intk } \mathrm{C}(\mathrm{mg} / \mathrm{kg} / \mathrm{day})=\left[\mathrm{C}_{\text {medium }} \times \mathrm{CR} \times \mathrm{CF} \times \mathrm{FI} \times \mathrm{ABS}_{\mathrm{f}} \times \mathrm{EF} \times \mathrm{ED}\right] /[\mathrm{BW} \times \mathrm{AT}] \quad \mathrm{Eq} 1
$$

Intk C stands for Intake Concentration, which in the above exemplary exposure equation is ingestion, is used later as an input to the Target (or Receptor) Concentration Analysis (TC) module (Section 3.1.4.3) (16, 17, 36). This way outputs of this module (Ex Quan) become inputs to the TC module for a range of combinations of hazards, pathways and receptors / targets. The other abbreviations in this equation stand for these components:

$\mathrm{C}_{\text {medium }}=$ Contaminant concentration in the exposure medium of concern $\left(\mathrm{mg} / \mathrm{m}^{3}\right.$ for air; $\mu \mathrm{g} / \mathrm{L}$ for water; or $\mathrm{mg} / \mathrm{kg}$ for soil) - this can be referred to as Ex MCf (Exposure Medium Concentration - final). Numeric values of Ex MCf (as an input to this module i.e. Ex Quan), will come (as an output) from the module 'Pathway Concentration Analysis (of hazards)' in Section 3.1.4.2 - where Ex MCf and its implications (along with corresponding maximum, minimum and most likely features) are explained. Simply, maximum, minimum and most likely ExMCf values will correspondingly yield maximum, minimum and most likely Intk C values.

$\mathrm{CR}=$ Contact rate $\left(\mathrm{m}^{3} / \mathrm{hr}\right.$ for air; $\mathrm{mg} /$ day for soil; or $\mathrm{L} /$ day for water)

$\mathrm{CF}=$ Conversion factor

$\mathrm{FI}=$ Fraction intake from contaminated source

$\mathrm{ABS}_{\mathrm{f}}=$ Bioavailability or absorption factor $(\%)$

$\mathrm{ET}=$ Exposure time (hours/day)

$\mathrm{EF}=$ Exposure frequency

$\mathrm{ED}=$ Exposure duration (years)

$\mathrm{BW}=$ Body weight $(\mathrm{kg})$

$\mathrm{AT}=$ Averaging time (days)

$$
\text { Intk } \mathrm{C}=\mathrm{C}_{\text {medium }} \mathrm{x} \text { IR } \mathrm{x} \mathrm{ED} \quad \mathrm{Eq} 2
$$


This is another but simple form of an intake (or ingestion) exposure equation:

Intk $\mathrm{C}=$ Same as in Eq 1, abve.

$\mathrm{C}_{\text {medium }}=$ Same as in Eq 1, above.

$\mathrm{IR}=$ Also called 'contact rate' is amount of polluted exposure medium contacted or in-taken per unit time or event.

$\mathrm{ED}=$ Exposure Duration (could be in time or number of events, etc.)

\subsubsection{Concentration Assessment (CA)}

Like the Ex A, the Concentration Assessment section is also a fundamental stage of a risk assessment process in which concentrations of all possible hazards are estimated or measured in four categories described below:

1. Concentrations of hazards at the pollutant source (i.e. landfill as contaminated site);

2. Concentrations across links or media of pathways, mainly exposure medium;

3. Concentrations at the target location (both background and reaching (or intake) concentrations); and

4. Critical (or threshold) concentrations against which hazards' concentrations are compared and controlled.

The concentration assessment allows demonstrating that the degree of risk is significantly dependent on the concentration of a given hazard that reaches a given receptor / target; enters the target's boundaries; and the safe and acceptable level of hazard concentration for the given target. In line with the list of the four items above, the CA is divided into four modules: 1) Source Concentration Analysis (Sorc C), 2) Pathway Concentration Analysis (PC), 3) Receptor or Target Concentration Analysis (TC) and 4) Critical Concentration Analysis (Cri C).

\subsubsection{Source Concentration Analysis module (Sorc C)}

In the Sorc $\mathrm{C}$ module, concentrations of the leachate properties and pollutants in the landfill body, which were identified earlier in the $\mathrm{H}$ Iden module, are quantified and described. Statistical descriptions can be employed to workout maximum, mean, mode and minimum concentrations to address temporal and spatial variations in the pollutant source i.e. the contaminated site. 


\subsubsection{Pathway Concentration Analysis module (PC)}

$\mathrm{PC}$ is further divided into two sub-modules, Pre Ex MC and Ex MC, representing Pre-Exposure Medium Concentration Assessment and Exposure Medium Concentration Assessment, respectively. The former sub-module involves concentration analysis of hazards in all the links of a given pathway that lie between the pollutant source / contaminated site and a given exposure medium of a given target / receptor. These links may include unsaturated zone, saturated zone, aquifer, etc. depending upon the nature of a given scenario. The latter sub-module (Ex MC), however, deals specifically with the exposure medium for a given target, in terms of concentration analysis of hazards. Examples of exposure medium are groundwater abstraction point in an aquifer and a case where water flows from an aquifer into a river. (18).

Ex MC can be then further divided into these three sub-modules (as also shown in Figure 1): Ex MCi (Exposure Medium Concentration - Initial or Background), Ex MCr (Exposure Medium Concentration - Reaching) and Ex MCf (Exposure Medium Concentration - Final). The first two of these three sub-modules are to be added together according to the nature, size and concentration of the two streams, using a mass balance equation approach to estimate for the third sub-module. The following equation can be used to obtain the final concentration of a given hazard in the exposure medium (Ex MCf):

$$
\text { Ex MCr x mr }+ \text { Ex MCi x } m_{i}=\operatorname{Ex} \operatorname{MCf} \times m_{f}
$$

Eq 3

Where, $\mathrm{m}_{\mathrm{r}}, \mathrm{m}_{\mathrm{i}}$, and $\mathrm{m}_{\mathrm{f}}$ are masses of the exposure medium - reaching, exposure medium - initial and exposure medium - final, respectively. If all streams are flowing then mass 'flow rate' balance equation can be used. For example, in case of an aquifer and river, both streams are flowing. For a static water course, there is a need for further research that falls beyond the scope of this study. Statistical descriptions can be applied to this module to workout maximum, minimum and most likely values of Ex MCf which can be used as inputs in exposure equations in the Ex Quan module (above, Section 3.1.3.4) to correspondingly calculate maximum, minimum and most likely exposures. This explains how outputs of this module are employable as inputs to the Ex Quan module. 


\subsubsection{Target (or Receptor) Concentration Analysis module (TC)}

Like the Ex MC sub-module, the TC module has also been categorised into three sub-modules namely, TCi (Target Concentration - Initial or background concentration), Intk C (Intake Concentration i.e. hazard concentration entering boundaries of a given target / receptor) and TCf (Receptor or Target Concentration - Final). Like the case of Ex MC, the first two when summed up using a mass balance approach gives the value of the final concentration of a given hazard in the target (i.e. TCf). The mass balance has to account for the nature, size and concentration of the two streams i.e. TCi and IntkC. The word 'nature' has been used in relation to whether it is a living target / receptor such as human, flora, fauna or non-living targets / receptors such as water courses (like a river). For example, consider Mercury $(\mathrm{Hg})$ as a given hazard. In the case of a river being the target it is necessary and practicable to consider $\mathrm{Hg}$ background concentration in the river. Whereas if the target is a living, for example a specific bird species, then the background concentration of $\mathrm{Hg}$ in bodies of the bird species (i.e. the target / receptor) may not be significant and / or may be difficult to measure in a comparative manner. All types of aforesaid concentrations can be measured applying statistical descriptions. The consideration of maximum, most likely and least concentrations of hazards as in $\mathrm{TCi}$ and Intk $\mathrm{C}$ would assist in estimating the corresponding maximum, most likely and least TCf values. Numeric values of Intk C, however, are derived in the form of exposure in the Ex Quan module (Section 3.1.3.4 where some examples of exposure equations are described). In this way, outputs of the Ex Quan module in the form of Intk C values become inputs to the TC module to calculate TCf values. However, Intk C is simply equal to TCf, if TCi values are negligible. Later, TCf values from this module are used as inputs to the three modules of Risk Characterisation (Section 3.2.4) in calculating respective hazard indices and risks.

\subsubsection{Critical Concentration Analysis module (Cri C)}

Various terms have interchangeably been used in the literature to describe Critical Concentration, including trigger levels, safe limits, acceptable levels, standards, threshold levels, control limits, reference dose, potency factor, slope factor, unit cancer risk, etc. (1, 12, 18, 19). However, Critical Concentrations are preferably obtained directly from legislation and regulations. They may also be determined from items such as Reference Dose (RfD) and Unit Cancer Risk (UCR) in the literature, depending upon characteristics of a given scenario and that of a given target / receptor in particular (18). RfD is generally used in connection to non-carcinogenic hazards, while UCR, for carcinogenic hazards. However, they both are Cri C effectively in their respective spheres. Also, if a target / receptor is a tissue of a biotic (e.g. a mice, a human) then $\mathrm{RfD}$ is a more reasonable term to use for 
non-carcinogenic hazards. Whereas if the target / receptor is a non-living (e.g. a river) then RfD will not make sense (even for a non-carcinogenic hazard). Thus, this paper introduces the term Cri $\mathrm{C}$ as a 'holistic' term which encapsulates all the types for all possible scenarios. Irrespective of implications of the term, once Cri C and TCf values are established for hazards in a given landfill scenario, the RA process then can lead further to the R Esti stage of the holistic framework.

\subsection{The Risk Estimation (R Esti)}

\subsubsection{Migration Assessment (Migra A)}

Migration Assessment is a section of the RA framework which considers transfer and fate of (pollutant and property) hazards of leachate via various media / links of pathways from the pollutant source to environmental targets / receptors. This section consists of two modules (see Figure 1):

(i) Migration which regards transfer of leachate as a physical phenomenon in itself. This module addresses aspects like dispersion, advection, and retardation.

(ii) Attenuation which considers variation of qualities of leachate as it moves. These variations could be due to biological, physical and / or chemical reactions. Examples are sorption (adsorption and absorption), cation exchange reactions, and dilution.

In the light of the Sorc Iden, P Iden and T Iden modules of Ex A, the Migra A section will allow to estimate or measure concentrations of leachate hazards not only at the pollutant source site itself but also other links of the pathway like exposure medium in particular. These concentration values are used in the CA and Ex Quan modules and sub-modules of the RA structure. The observation gained here demonstrates again how the framework addresses the aspect of mutual information transfer between modules and sub-modules of the RA process.

A range of tools such as LandSim $(1,2,9)$ are available which a risk assessor may consider to use if appropriate and suitable to characteristics of a given risk analysis scenario to estimate likely hazard concentrations at, for example, groundwater abstraction point over time. Consideration of temporal and spatial variations and employment of statistical descriptions can assist to obtain more sitespecific estimations. All encountered uncertainties and limitations can be mentioned clearly in the Uncertainty Assessment (UA) section of the RA framework (discussed below in Section 3.2.3). 


\subsubsection{Significance Assessment (Sig A)}

The Significance Assessment is an aspect introduced to the RA methodology framework to allow the risk assessor to establish which modules, sub-modules and parameters are important to be considered (and in what prioritization order), and which ones are insignificant to be dropped out / eliminated from the risk analysis process of a given site. The risk assessor is to explain reasons of these considerations and eliminations as this will assist, for instance, site managers and / or risk managers and other relevant stakeholders in making their risk control decisions. For instance, in an arid area such as Saudi Arabia the rainfall is minimal (insignificant to form leachate in large amounts) as opposed to the UK where precipitation occurs all round the year, which can contribute to large amount of leachate generation. Thus, the Sig A facet of the framework will prevent risk assessors from covering every conceivable unnecessary situation in a given risk analysis exercise, which can also be called the process of elimination. Therefore, this aspect is common to all modules, sub-modules and parameters of the RA framework and it does not directly contribute to Risk Quantification. In summary, the Sig A facet helps to deselect insignificant elements, select significant and appropriate elements and yet prioritise selected elements in the risk assessment exercise of a specific landfill scenario.

\subsubsection{Uncertainty Assessment (UA)}

Uncertainties are immeasurable or non-estimated risks and can arise from several sources, including natural or inherent variability over space and time, variability in the accuracy of measurements and data manipulation, and knowledge gaps due to lack of data (4). The UA section constitutes the RA methodology framework to assist risk assessors to analyse uncertainties at different stages of the RA process for a given contamination site. Like the Sig A, the UA is also common to all modules, sub-modules and parameters of the framework. However, in this section a range of different types of uncertainties are listed below which a risk assessor can use as a checklist to consider uncertainties at various RA stages:

- Limitations of measuring instruments under the prevailing operating conditions;

- Data manipulation such as averaging out, the local variation in concentration of a pollutant in a given site, variation in precipitation, groundwater level fluctuation;

- Data interpretation in the relevant literature (such as the reading and estimation from precipitation maps; extrapolation of animal data in toxicology, epidemiology, industrial hygiene, health physics); 
- Spatial variations;

- Temporal variations;

- Knowledge gaps such as limitations of knowledge of toxicology; and

- Limitations of models being applied (such as LandSim yields more accurate results if targets are not far from the pollutant source).

In fact, all uncertainties involved in a RA should be estimated and accounted for when appropriate and possible. Whether estimation is possible or not, in either case uncertainties involved in any factors of the RA process should be clearly described to assist decision-making regarding risk control measures.

\subsubsection{Risk Characterisation (R Cha)}

Risk from a hazard, which may be a substance, a process / activity, a property / characteristic or other factors such as a layout, is the measure of likelihood or degree of possibility (or probability / chance) that the hazard will cause harm in actual circumstances of use (adapted from 13, 14, 19). According to the Environment Agency $(2,9)$, an equation of risk can be expressed as following:

$$
\text { Risk }=(\text { Chance }) \times(\text { Outcome }) \quad \text { Eq } 4
$$

While, Jaggy (20) defined a risk more statistically as follows:

$$
\text { Risk }=(\text { Probability of an undesired event }) \times \text { (Impact of the event) Eq } 5
$$

In the above equations, chance or probability constitutes the quantitative part of risk whilst outcome or impact denotes the qualitative factor. In the context of this research study, the 'chance' part of risk is regarding the reaching (and / or building up) of a certain concentration of a pollutant in a target / receptor body. Where as the impact that the concentration can yield (e.g. contracting headache, developing cancer, etc.) is the unwanted 'outcome' part of the risk.

The Risk Characterisation (RCha) is the final step in the RA framework. At this stage, the assessment of exposures and hazards' concentrations carried out in the HA process, are summarised and integrated into quantitative and qualitative expressions of risk. Major assumptions, scientific judgements (by experts when data is either not available or is of poor quality), and to the extent possible, estimates of the uncertainties embodied (in various modules and sub-modules of the RA 
process) can also be highlighted in this module (12). In the RA framework, the R Cha is divided into three modules as follows: 1) Hazard Indices, 2) Carcinogenic Risk and 3) Non-carcinogenic Risk. These are illustrated in Figure 1 and described below.

\subsubsection{Hazard Index / Hazard Indices module (HI)}

Generally HI is the ratio of the target intake concentration to the critical concentration (Cri C) (21, 22). However, this research study, as explained earlier in Section 3.1.4.3, suggests that TCf is compared with Cri C, rather than just the target intake concentration, in order to account for hazard concentration already or initially present in the target / receptor boundaries, if appropriate. Thus, Hazard Index (HI) should be considered as the ratio of TCf and Cri C for a given combination of hazard, pathway and target / receptor. In this case, HI can be expressed as the ratio of these two parameters as follows:

$$
\mathrm{HI}=\mathrm{TCf} / \mathrm{Cri} \mathrm{C}
$$

The consideration of a maximum TCf value to calculate HI ratio would result in the maximum value of HI and thus an indication of risk for a worst case scenario. On the other hand, using an average TCf value would yield the average HI value corresponding to the most likely scenario of risk. An innovative concept that this research introduces in this regard is that of 'least bad' scenario of risk in which the minimum value of TCf is considered to yield minimum HI value. Thus, there can be three streams of HI values, that is the maximum, average and minimum, which will reflect on the worst case, the most likely and the least bad scenarios of risk, respectively. The most likely scenario of risk must not be falling outside the range between the worst case and the least bad scenarios, which can be deemed as benchmarks sitting on the two extreme ends of the scale. This way, this 'triple-stream' approach can also be employed as a 'double-check' whether risk assessment is yielding reasonable results. As far as Cri $\mathrm{C}$ value is concerned, the more the conservative $\mathrm{Cri} \mathrm{C}$ is, the more the conservative $\mathrm{HI}$ value will be derived. For a risk assessment to be on the most conservative side, the highest conservative value of $\mathrm{Cri} \mathrm{C}$ will need to be considered for all individual hazards, and the vice versa.

Unlike the other two modules of R Cha (i.e. Carcinogenic Risk and Non-carcinogenic Risk, discussed below), while working out $\mathrm{HI}$ values in this module, no discrimination between carcinogenic and non-carcinogenic hazards is made. However, if a given target / receptor is, for example, a human or mammal for which carcinogenic and non-carcinogenic classification makes 
sense, the other two modules of R Cha can be considered. But if a given target is, for instance, a river or groundwater then carcinogenic and non-carcinogenic classification is of no significance as a river or groundwater cannot "develop cancer", and consequently the other two modules will be of no significance to consider in such a scenario. However, irrespective of a risk analysis process being taken up to the stage of the other two modules or not, the HI module can still be useful as a standalone module in providing an overall picture for all hazards exposed to all targets / receptors via all pathways in a given scenario. In the case of carcinogenic hazards, HI would be a comparison between TCf and Cri C, in which Cri $\mathrm{C}$ would be corresponding to acceptable risk level such as one in a million. For non-carcinogenic hazards, HI would still be the ratio between TCf and Cri C but the Cri C is generally a Reference Dose (RfD). This concept is elaborated further in the other two modules of R Cha below.

Once HI values have been worked out for all contaminants in a given landfill scenario, then a risk assessor can identify the ones which have values more than or equal to unity, as those hazards would be the ones with concentrations beyond safe levels. As a general rule, the higher the HI value, the greater the risk of the adverse affect. For a target / receptor such as a river, if a HI value is greater than or equal to unity for a hazard (either carcinogenic or non-carcinogenic) then there is risk that the river will be polluted. Conversely, if the HI is less than unity, then it will not be considered as river is polluted (for natural self purification will address this low degree of contamination). Whereas if a given target / receptor is a human, then the HI value greater than or equal to unity for a carcinogenic hazard would mean there is a risk of one in a million humans to suffer from cancer (if one in a million is the acceptable level). Conversely, if the HI is less than one, there is an acceptable degree of the risk i.e. one in a million contracting cancer, as in the cancer science a general presumption made is that for a carcinogenic hazard, any concentration poses a degree of risk of developing cancer, i.e. risk can not be zero. In the case of a non-carcinogenic hazard and a human as a target / receptor, HI value more than or equal to one would imply that there is a risk for a non-cancer adverse affect (such as headache) to occur. However, if HI is less than unity, then the headache will not occur, as in the toxicology science it is believed that at a concentration less than the RfD will be addressed by natural immune system of the target / receptor body.

The total hazard index (THI) of all the hazards for a given combination of a pathway and target / receptor in a given landfill scenario, can be calculated by adding all the individual hazard indices as presented in the mathematical expression below $(12,22)$ : 


$$
\mathrm{THI}_{\mathrm{H}}=\sum_{i=1}^{l} \mathrm{TCf}_{\mathrm{i}} / \mathrm{Cri} \mathrm{C}_{\mathrm{i}}
$$

Where, $\mathrm{THI}_{\mathrm{H}}=$ Total Hazard Index for all the hazards of the landfill scenario for one combination of a specific pathway and a specific target / receptor.

$\mathrm{TCf}_{\mathrm{i}}=$ Receptor or Target Concentration - Final (or Intake Concentration / dose if the target background concentration is negligible or zero) of $\mathrm{i}^{\text {th }}$ hazard / $(\mathrm{mg} / \mathrm{kg} /$ day $)$.

Cir $\mathrm{C}_{\mathrm{i}}=$ Critical Concentration of $\mathrm{i}^{\text {th }}$ hazard (mg/kg/day).

$l=$ Total number of hazards for the landfill scenario

This research study presents an innovative approach that the THI for all the pathways for a given combination of a hazard and target / receptor can be calculated by adding all the individual hazard indices as presented in the mathematical expression below:

$$
\mathrm{THI}_{\mathrm{P}}=\sum_{j=1}^{m} \mathrm{TCf}_{\mathrm{j}} / \mathrm{Cri} \mathrm{C}_{\mathrm{j}}
$$

$\mathrm{Eq} 7 \mathrm{~b}$

Where, $\quad \mathrm{THI}_{\mathrm{P}}=$ Total Hazard Index for all the pathways of the landfill scenario for one combination of a specific hazard and a specific target.

$\mathrm{TCf}_{\mathrm{j}}=$ Receptor or Target Concentration - Final (or Intake Concentration / dose if the target background concentration is negligible or zero) of the hazard via $\mathrm{j}^{\text {th }}$ pathway (mg/kg/day).

Cri $C_{j}=$ Critical Concentration of the hazard / contaminant via $j^{\text {th }}$ pathway ( $\left.\mathrm{mg} / \mathrm{kg} / \mathrm{day}\right)$. $m=$ Total number of pathways for the described scenario.

Similarly, another innovative approach, this paper introduces is that the THI for all the targets / receptors for a given combination of a pathway and hazard can be calculated by adding all the individual hazard indices as presented in the mathematical expression below:

$$
\mathrm{THI}_{\mathrm{T}}=\sum_{k=1}^{n} \mathrm{TCf}_{\mathrm{k}} / \mathrm{Cri} \mathrm{C}_{\mathrm{k}}
$$

Where, $\quad \mathrm{THI}_{\mathrm{T}}=$ Total Hazard Index for all the targets / receptors of the landfill scenario for one combination of a specific pathway and a specific hazard. 
$\mathrm{TCf}_{\mathrm{k}}=$ Receptor or Target Concentration - Final (or Intake Concentration / dose if the target background concentration is negligible or zero) of the hazard / contaminant for $\mathrm{k}^{\text {th }}$ target / receptor $(\mathrm{mg} / \mathrm{kg} /$ day).

Cir $\mathrm{C}_{\mathrm{k}}=$ Critical Concentration of the hazard / contaminant for $\mathrm{k}^{\text {th }}$ target $/$ receptor $(\mathrm{mg} / \mathrm{kg} /$ day $)$.

$n=$ Total number of targets / receptors for a described scenario.

The overall THI due to all the hazards (Eq 7a) via all the respective pathways (Eq 7b) for all the respective targets / receptors $(\mathrm{Eq} 7 \mathrm{c})$ in a given landfill scenario, can be determined by aggregating each individual case as follows:

$$
\text { Overall THI }=\sum_{i=1}^{l} \mathrm{TCf}_{\mathrm{i}} / \mathrm{Cri}_{\mathrm{i}}+\sum_{j=1}^{m} \mathrm{TCf}_{\mathrm{j}} / \mathrm{Cri} \mathrm{C}_{\mathrm{j}}+\sum_{k=1}^{n} \mathrm{TCf}_{\mathrm{k}} / \mathrm{Cri} \mathrm{C}_{\mathrm{k}} \quad \text { Eq 7d (i) }
$$

Equation $7 \mathrm{~d}(\mathrm{i})$ can also be expressed as:

$$
\text { Overall THI }=\sum_{i, j, k=1}^{l, m, n} \mathrm{TCf}_{\mathrm{i}, \mathrm{j}, \mathrm{k}} / \mathrm{Cri} \mathrm{C}_{\mathrm{i}, \mathrm{j}, \mathrm{k}} \quad \text { Eq 7d (ii) }
$$

Where, Overall THI = Cumulative hazard index value of all the hazards, all the pathways and all the targets / receptors in a given landfill scenario.

$\mathrm{TCf}_{\mathrm{i}, \mathrm{j}, \mathrm{k}}=$ Receptor or Target Concentration - Final (or Intake Concentration / dose if the target background concentration is negligible or zero) for $\mathrm{i}^{\text {th }}$ hazard / contaminant via $\mathrm{j}^{\text {th }}$ pathway for the $\mathrm{k}^{\text {th }}$ target / receptor ( $\mathrm{mg} / \mathrm{kg} / \mathrm{day}$ ).

Cir $\mathrm{C}_{\mathrm{i}, \mathrm{j}, \mathrm{k}}=$ Critical Concentration for $\mathrm{i}^{\text {th }}$ hazard / contaminant via $\mathrm{j}^{\text {th }}$ pathway for the $\mathrm{k}^{\text {th }}$ target / receptor $(\mathrm{mg} / \mathrm{kg} / \mathrm{day})$.

$l, m$ and $n=$ Total number of hazards, pathways, and targets / receptors, respectively, for a landfill given scenario.

If the overall aggregated value of THI is less than unity then it implies that there is no single hazard exceeding its respective safe (or critical) level via any pathway to any target / receptor. And if the overall THI is greater than or equal to unity, a risk assessor has to then identify which individual combinations of a hazard, pathway and target / receptor are exceeding their respective safe (or Cri C) level. 


\subsubsection{Carcinogenic Risk module (R Carci)}

Carcinogenic risk is the probability or chance of a target / receptor to develop cancer over a given time scale. For carcinogens, risks are estimated as the incremental probability of an individual developing cancer over a lifetime as a result of exposure to the potential carcinogen (12). Unlike non-carcinogens, carcinogens are considered 'non-threshold'. That is, in the cancer science it is assumed that there is no level of concentration of a carcinogenic hazard that does not pose some probability of producing a carcinogenic response. In other words, any lowest concentration of a carcinogenic hazard, poses some degree of risk of developing cancer.

The Unit Cancer Risk (UCR), also called Potency Factor (PF) or Slope Factor (SF), converts estimated daily dose intakes averaged over lifetime of exposure directly to incremental risk of an individual developing cancer. UCR is the reciprocal of the concentration of a carcinogen measured in milligrams per kilogram of animal body or human body weight per day. Mathematically it is expressed as:

$$
1 /\left(\mathrm{mg} \mathrm{kg}^{-1} \text { day }^{-1}\right)=\mathrm{mg}^{-1} \mathrm{~kg}^{\text {day }} \quad \mathrm{Eq} 8
$$

UCR can also be defined as the risk produced by a life time average daily dose of $1 \mathrm{mg} \mathrm{kg}^{-1} \mathrm{day}^{-1}$. As relatively low intakes (compared to those experienced by test animals) are most likely from environmental exposures, it generally can be assumed that the dose-response relationship will be linear in the low-dose portion of a dose-response curve. Under this assumption, the UCR is a constant and risk will be directly related to intake. Thus, the linear form of the carcinogenic risk equation is usually applicable for estimating carcinogenic risks $(12,23)$. The linear low-dose equation is described below $(12,21)$. There are many mathematical models available, including the multistage model, the linear multistage model, the one-hit model, the multi-hit model, and the probit model (23). A risk assessor may decide to use any model depending on the scenario and the availability of data and desired outcomes. A toxicologist may also be consulted not only for the selection of a model out of the above list but also for working out critical concentrations of both carcinogenic and non-carcinogenic hazards, particularly if this information is not readily available in the literature.

Carcinogenic risk can be expressed as follows:

$$
\mathrm{R}=\mathrm{TCf} \times \mathrm{EqR}
$$


Where, $\quad \mathrm{R}=$ Carcinogenic risk is the probability of an individual developing cancer over given time period. Risk is a dimensionless parameter and thus has no unit.

$\mathrm{TCf}=$ Final concentration of a carcinogen in the boundaries of the target $/$ receptor. TCf would be Intake Dose / Concentration if initial carcinogen concentration in the target / receptor is negligible or zero. Generally this would be chronic daily intake averaged over 70 years. The unit of TCf is $\mathrm{mg} / \mathrm{kg} /$ day $\mathrm{UCR}=$ Unit Cancer Risk $\left(\mathrm{mg}^{-1} / \mathrm{kg} /\right.$ day $)$ for a given carcinogenic hazard.

In line with the description immediately after Equation 6 (Section 3.2.4.1, paragraph 2), the consideration of the maximum, average and minimum TCf values for a given combination of a hazard, pathway and target / receptor in Equation 9 will yield the worst case, most likely case and least bad risk scenarios, respectively. Similarly, the concepts of triple-stream and double-check are also equally applicable here. As far as UCR value is concerned, the more the conservative UCR is, the more the conservative risk value will be. For a risk assessment to be on the most conservative side, the highest conservative value of UCR needs to be considered for all individual carcinogenic hazards.

Unlike non-carcinogens, RA for carcinogens emphasises the overall aspect of carcinogenic risk. For instance, in a given scenario, if there is a risk of 1 in a million for developing lung cancer and 3 in a million for developing liver cancer, then the overall risk of cancer would be 4 in a million, irrespective of which organs develop cancer (10). Thus, in the context of risks aggregation for carcinogens, RA is not organ-specific, whereas for non-carcinogens, RA is generally organ-specific. Furthermore, in carcinogenic RA, estimating risk by considering only one hazard at a time might significantly underestimate the risks associated with simultaneous exposures to several hazards / chemicals. For instance, if an acceptable level of risk is 2 in a million in a given carcinogenic RA scenario. Then considering only lung cancer case (i.e. 1 in a million) in the above example, will be deemed safe, which will be an understatement as liver cancer risk (i.e. 3 in a million) is not taken into account yet. Therefore, in order to have a complete carcinogenic risk picture, the two should be considered together. Thus, the total risk, which is 4 in a million, is exceeding the acceptable level of (i.e. 2 in a million) risk by twice as much. This illustrative case demonstrates that a total risk from all carcinogenic hazards needs to be determined.

The total risk (TR) of all the carcinogenic hazards for a given combination of a pathway and target / receptor in a given landfill scenario can be calculated by adding all the individual multiplications of 
each carcinogenic hazard's TCf and its respective UCR, as presented in the mathematical expression below $(12,22)$ :

$$
\mathrm{TR}_{\mathrm{H}}=\sum_{i=1}^{l} \mathrm{TCf}_{\mathrm{i}} \times \mathrm{UCR}_{\mathrm{i}} \quad \text { Eq 10a }
$$

Where, $\quad \mathrm{TR}_{\mathrm{H}}=$ Total Risk from all the carcinogenic hazards of the landfill scenario for one combination of a specific pathway and a specific target / receptor.

$\mathrm{TCf}_{\mathrm{i}}=$ Receptor $/$ Target Concentration - Final (or intake concentration / dose if target background concentration is negligible or zero) of $\mathrm{i}^{\text {th }}$ carcinogenic hazard (mg/kg/day).

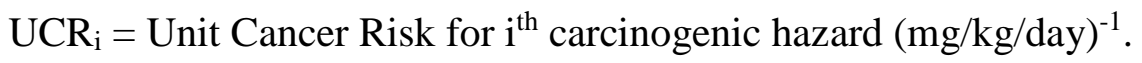

$l=$ Total number of hazards for the landfill scenario.

This research study presents an innovative approach that the TR for all the pathways for a given combination of a carcinogenic hazard and target / receptor can be calculated by adding all the individual multiplications of each carcinogenic hazard's TCf and its respective UCR, as presented in the mathematical expression below:

$$
\mathrm{TR}_{\mathrm{P}}=\sum_{j=1}^{m} \mathrm{TCf}_{\mathrm{j}} \times \mathrm{UCR}_{\mathrm{j}} \quad \mathrm{Eq} 10 \mathrm{~b}
$$

Where, $\quad \mathrm{TR}_{\mathrm{P}}=$ Total Risk for all pathways of the landfill scenario for one combination of a specific carcinogenic hazard and a specific target / receptor.

$\mathrm{TCf}_{\mathrm{j}}=$ Receptor or Target Concentration - Final (or intake concentration / dose if target background concentration is negligible or zero) of the carcinogenic hazard $v i a j^{\text {th }}$ pathway $(\mathrm{mg} / \mathrm{kg} /$ day).

$\mathrm{UCR}_{\mathrm{j}}=$ Unit Cancer Risk for the carcinogenic hazard via $\mathrm{j}^{\text {th }}$ pathway $(\mathrm{mg} / \mathrm{kg} / \mathrm{day})^{-1}$. $m=$ Total number of pathways for a described scenario.

Similarly, another innovative approach, this paper introduces is that the TR for all the targets / receptors for a given combination of a pathway and a hazard can be calculated by adding all the individual multiplications of each carcinogenic hazard's TCf and its respective UCR, as presented in the mathematical expression below: 


$$
\mathrm{TR}_{\mathrm{T}}=\sum_{k=1}^{n} \mathrm{TCf}_{\mathrm{k}} \times \mathrm{UCR}_{\mathrm{k}} \quad \mathrm{Eq} 10 \mathrm{c}
$$

Where, $\quad \mathrm{TR}_{\mathrm{T}}=$ Total Risk for all the targets / receptors of the landfill scenario for one combination of a specific pathway and a specific hazard.

$\mathrm{TCf}_{\mathrm{k}}=$ Receptor or Target Concentration - Final (or Intake Concentration / dose if the target background concentration is negligible or zero) of the hazard / contaminant for $\mathrm{k}^{\text {th }}$ target / receptor ( $\mathrm{mg} / \mathrm{kg} /$ day)

$\mathrm{UCR}_{\mathrm{k}}=$ Unit Cancer Risk for the carcinogenic hazard for $\mathrm{k}^{\text {th }}$ target $/$ receptor $(\mathrm{mg} / \mathrm{kg} / \mathrm{day})^{-1}$.

$n=$ Total number of targets for a described scenario.

The overall TR from all the hazards (Eq 10a) via all the respective pathways (Eq 10b) to all the respective targets / receptors (Eq 10c) in a given landfill scenario, can be derived by aggregating each individual case as follows:

$$
\text { Overall TR }=\sum_{i=1}^{l} \mathrm{TCf}_{\mathrm{i}} \times \mathrm{UCR}_{\mathrm{i}}+\sum_{j=1}^{m} \mathrm{TCf}_{\mathrm{j}} \times \mathrm{UCR}_{\mathrm{j}}+\sum_{k=1}^{n} \mathrm{TCf}_{\mathrm{k}} \times \mathrm{UCR}_{\mathrm{k}} \quad \text { Eq 10d (i) }
$$

Equation 10d (i) can also be expressed as:

$$
\text { Overall TR }=\sum_{i, j, k=1}^{l, m, n} \mathrm{TCf}_{\mathrm{i}, \mathrm{j}, \mathrm{k}} \times \mathrm{UCR}_{\mathrm{i}, \mathrm{j}, \mathrm{k}} \quad \text { Eq 10d (ii) }
$$

Where, Overall TR $=$ Cumulative risk value of all the carcinogenic hazards, all the pathways and the targets / receptors in a given landfill scenario.

$\mathrm{TCf}_{\mathrm{i}, \mathrm{j}, \mathrm{k}}=$ Final concentration of the hazard in the target $/$ receptor or intake concentration / dose (if target background concentration is negligible or zero) for $\mathrm{i}^{\text {th }}$ carcinogenic hazard via $\mathrm{j}^{\text {th }}$ pathway for $\mathrm{a}^{\text {th }}$ target / receptor $(\mathrm{mg} / \mathrm{kg} / \mathrm{day})$.

$\mathrm{UCR}_{\mathrm{i}, \mathrm{j}, \mathrm{k}}=$ Unit Cancer Risk for $\mathrm{i}^{\text {th }}$ carcinogenic hazard via $\mathrm{j}^{\text {th }}$ pathway for a $\mathrm{k}^{\text {th }}$ target $/$ receptor $(\mathrm{mg} / \mathrm{kg} / \text { day })^{-1}$.

$l, m$ and $n=$ Total number of hazards, pathways, and targets / receptors, respectively, for a given scenario. 
If the overall aggregated value of TR is less than the acceptable level of risk (e.g. one in a million), then it implies that there is no single hazard exceeding its respective critical level (i.e. the UCR) via any pathway to any target / receptor. And if the overall TR is greater than or equal to the acceptable level of risk, a risk assessor has to then identify which individual combinations of a hazard, pathway and target / receptor are exceeding their respective UCR level.

\subsubsection{Non-Carcinogenic Risk module (R Non-carci)}

A non-carcinogenic risk can be stated as the chance of a target / receptor to suffer a non-cancerous adverse health affect (such as skin infection, headache) from a non-carcinogenic hazard over a given time scale. In contrast to carcinogenic risk, non-carcinogenic risk assumes that some threshold exists below which there is no occurrence of toxic response or adverse affect by virtue of the body's natural repair and detoxifying capacity. This threshold is called No Observed Adverse Effect Level (NOAEL). It is represented by the Reference Dose (RfD) of a substance, which (assuming zero background concentration) is the intake or dose of the substance per unit body weight per day (mg kg-1 $\left.\mathrm{day}^{-1}\right)$ that is likely to pose no appreciable risk to human populations, including such sensitive groups as children (23).

Non-carcinogenic risk is indicated by means of a HI and THI as already discussed in Section 3.2.4.1. However, Cri C (or RfD) for non-carcinogens can also be used for quantitative risk assessments in the following way (23):

$$
\text { Risk }=\text { PF }(\text { TCf }- \text { Cri C }) \quad \text { Eq } 11
$$

Where, PF = the potency factor of the slope of the dose-response curve, also called slope factor.

TCf $=$ final target concentration and would effectively be daily intake dose if initial or background target concentration is zero, and

Cri $\mathrm{C}=\mathrm{RfD}$ in this case

As explained earlier (Section 3.2.4.1), the maximum, average and minimum TCf values for a given combination of a hazard, pathway and target / receptor would result in the worst case, most likely case and least bad risk scenarios, respectively. If the above non-carcinogenic risk expression (i.e. Eq 11 ) is applied for non-carcinogenic hazards, then total (non-carcinogenic) risks can be calculated in a similar way to Equations 10a, 10b, 10c and 10d, as presented for carcinogenic hazards in Section 3.2.4.2. However, in general, the HI approach (i.e. the ratio of TCf and Cri C) is used as an 
indicator of risk potential for non-carcinogens rather than the risk expression given above in Equation 11 (23). By simply algebraically aggregating the two individual 'overall TRs' of the carcinogenic and non-carcinogenic parts, a Grand Overall TR can be derived for a given landfill scenario.

\subsubsection{Risk Reduction (RR)}

This is the third main part of Risk Management (RM) as shown in Figure 1. This section does not fall in the main scope of the paper but still briefly describes to outline the risk assessment methodology's position in and connectivity with the risk management phenomenon. The RR part comprises a number of modules and sub-modules such as Risk Evaluation (R Eva), Risk Control (R Cntrl), Consequences Evaluation (Conse Eva), Costs Evaluation (Costs Eva), Risk Monitoring (R Monit), and Corrective Action. In the R Eva module, the ripple effect or chain of subsequent consequences or potential losses are evaluated on a wider-scale by assuming the hazards would have eventually caused the identified potential harm (be it the pollution of a groundwater, the contamination of a food chain say fish in a river, etc.). R Eva can reveal further significance of a certain risk. For instance;

- If a given hazard / contaminant enters a surface water course (such as a lake) and kills a number of aquatic species then what are the effects that the absence of these species will have on the ecosystem of the region?

- If a given hazard pollutes the groundwater that is the supply source for agricultural or horticultural practices in the region then what impacts this will have on the local economy?

Risk evaluation is concerned with determining the sensitivity of the estimated risks for those affected, therefore it, additionally, includes the element of risk perception (24). As risk perception is the overall view of risk held by a person or group of people, sociological factors such as one's feelings and judgements, should be considered in the risk assessment process (24). As shown in Figure 1, however, this sociological evaluation needs to be considered alongside technical evaluation to ensure a holistic assessment approach is maintained.

The Conse Eva module assists the risk assessor to prioritise the hazards and risks in terms of their significance and ultimately contributes in prioritising the options of risk control. Subsequent to prioritisation, the cost analysis of those options can then be carried out to assess their cost- 
effectiveness on individual basis, thereby, further prioritising the matter in the light of 'sustainable development' philosophy.

\subsection{DISCUSSION AND CONCLUDING REMARKS}

The paper describes a relationship between hazard assessment, risk estimation, risk analysis, and risk reduction, thereby describing risk management as a superset, which encapsulates all of these items. Furthermore, the risk assessment is a key factor for an effective risk control, as the degree of success in achieving of the latter is based on effective implementation of the former. Despite this, a risk assessment methodology in a holistic format has yet to be presented in the literature for either landfills or any other contaminated land types. This study emphasises that the development and use of a holistic RA framework will help facilitate a more systematic and consistent process of risk analysis from the start (i.e. baseline study) through to the end (i.e. hazard indices and risk quantification). Thus, the paper presents a conceptual framework of the holistic methodology which clearly establishes and places together all factors and sub-factors of the total risk assessment process in a sequential and categorical manner. The framework also indicates how, when and where outputs of different sections and sub-sections of the risk analysis structure are inputs to other sections and sub-sections. Thus the framework maps the mutual information transfer among sections and subsections of the holistic risk analysis methodology.

The framework presented in this study provides a stronger base to perform risk analysis and consequently risk management, whereby risk assessment is increasingly becoming a legal requirement in different countries. Due to the degree of holism that this framework offers, issues of environmental integration, for instance, raised by the Water Framework Directive (27) and Habitats Directive (34), may well be taken into account. These include surface water, natural habitats, aquatic and terrestrial flora and fauna. The framework can also inform Environmental Impact Assessment (EIA) and Statement to identify and quantify impacts on the environment and its various species. This way the framework can assist more productively the implementation of the EIA Directive in Europe and the EIA Regulations in the UK $(42,43)$.

This framework can play an effective role in landfill planning permit requirements, landfill siting, design and construction as well as hazard mitigation measures. This framework can provide a greater degree of uniformity and consistency in risk assessments, thereby making it more feasible to compare estimated risks between different site locations for a given landfill, as well as various scenarios for the same landfill at the same location. This can also assist in siting a landfill where 
overall environmental risks are relatively low. Due to holistic and systematic standardisation that this framework is offering, not only risk comparison can become easier but also risk communication can be rendered more effective and efficient among diverse stakeholders, specially where conflicts regarding siting of waste disposal facilities is not uncommon (44).

It is appreciated that the conceptual framework, while generally accurate in concept, could be hard to implement due to its complexity. As acknowledged in the paper, there are often relationships among various sub-modules which can complicate its implementability and transferability, particularly depending on the degree of complexity of characteristics of a given landfill being assessed. However, such implications are not in the scope of this paper. The research outputs presented in this paper are undertaken chiefly with the idea of taking the current state-of-the-art risk assessment approach a step further, where the inherent complications and implications of integrating all modules and sub-modules of the total hazard and risk assessment process are considered in a quantitative context. Moreover, until such a conceptual framework is attempted to be developed (which this paper does), these complications and implications will not have an opportunity for further investigation and improvement. Therefore, despite the acknowledged complexities and challenges of such a comprehensive, holistic RA framework, the concepts presented in this paper provides an opportunity to build on existing models to the ultimate benefit of the environment.

In summary, this research work is a conceptual and indicative step in the direction of a holistic risk analysis approach, which can attract different interest groups from researchers in academe and risk practitioners in industrial and consultancy sectors for further investigation into wide ranging aspects. For instance, how to deal with likely complications resulting from integration between various steps and sub-steps of the total risk assessment methodology. In future, this conceptual methodology can be developed into a user-friendly computer-aided tool for holistic risk assessment of landfill leachate. Following further developments this tool could also be adapted around specifics of other types of contaminated land. However, the work presented in this paper is conceptual at this point, and paves a path for further research and development.

\section{AKNOWLEDGEMENTS}

The authors acknowledge the financial support of Dundee City Council in this project. We are additionally grateful for the discussion and help received from Mr Peter Goldie of the Environment \& Consumer Protection Department, Dundee City Council. The support from the University of 
Abertay Dundee (especially from Dr K. O. K. Oduyemi and Mr Phillip Jenkins); and Dr I. M. Spence (Consultant Environmental Geologist, Scotland) is also highly appreciated. It must be noted that concepts and ideas presented in this article by the authors do not necessarily represent views that of their respective employer organizations. 


\section{REFERENCES}

(1). Environment Agency. Hydrogeological risk assessments for landfill and the derivation of groundwater control and trigger levels, Environment Agency, 2003a

(2). Environment Agency. LandSim 2.5 - Groundwater risk assessment tool for landfill design. Environment Agency: Bristol, 2003b

(3) Environment Agency. Guidance on assessment of risks from landfill sites, External consultation version 1.0, Environment Agency: Bristol, (May) 2004

(4) DETR (Department of the Environment, Trade and the Regions), Environment Agency and the Institute for the Environment and Health. Guidelines for environment risk assessment and management. The Stationary Office: London, 2000

(5) Butt, T. E.; Lockley, E.; Oduyemi, K. O. K. Risk assessment of landfill disposal sites - state-ofthe-art, Waste Management Int. J., 2008, 28 (6), 952 - 964

(6) SI (Statutory Instruments) UK. Waste management licensing regulations 1994, SI No. 1056, Crown Copyright, 1994

(7) SI (Statutory Instruments) UK. Waste management licensing (Amendment and related provisions) Regulations 2005, SI No. 803, Crown Copyright, 2005

(8) Butt, T. E.; Oduyemi, K. O. K. Significance of baseline study in landfill risk assessment, Risk Analysis II - Second Int. Conf. on Computer Simulation in Risk Analysis and Hazard Mitigation, Bologna, Italy, pp. 93 - 103, 11 - 13 October 2000

(9) Environment Agency. LandSim performance simulation by Monte Carlo method (a LandSim software manual), Golder Associates Ltd, 1996

(10) Washburn, Stephen T. Managing Principal, Environ, USA. Pers. Commu., 2005

(11) Asante-Duah, D. K. Managing Contaminated Sites: Problem Diagnosis and Development of Site Restoration, John Wiley \& Sons Ltd, 1996

(12) EPA (Environmental Protection Agency) US. Risk assessment guidance for Superfund, Volume I, Human health evaluation manual (Part A), EPA/54011-89/002, USEPA Office of Emergency and Remedial Response: Washington, DC, 1989

(13) EHSC (Environment, Health and Safety Committee). Notes on Risk Assessment at Work, Version 2, RSoC (Royal Society of Chemistry), (June) 2002

(14) HSE (Health and Safety Executive). Five steps to risk assessment, Revision 1, HSE, (July) 2003

(15) Sara, N. M. Standard handbook for solid and hazardous waste facility assessments, Lewis Publishers - CRC Press, 1994 
(16) Daugherty, Jack. Assessment of chemical exposures - calculation methods for environmental professionals, Lewis Publishers - CRC Press, 1998

(17) DEFRA (Department for Environment, Food and Rural Affairs) and Environment Agency. The contaminated land exposure assessment model (CLEA): Technical basis and algorithms, R \& D Publication CLR 10, Document prepared by the National Groundwater and Contaminated Land Centre of the Environment Agency, 2002

(18) Butt, T. E.; Oduyemi, K. O. K. A holistic approach to concentration assessment of hazards in the risk assessment of landfill leachate, Environment International, Elsevier Science Ltd., 28 (7), $597-608,2003$

(19) HSE (Health and Safety Executive). COSHH (The new brief guidance for employers), Guidance on the main requirements of Control of Substances Hazardous to Health (COSSH) Regulations 1994, HSE, (May) 1996

(20) Jaggy, Michael. Risk analysis of landfills, Gheorghe, A.V. (Editor). Integrated regional health and environmental risk assessment and safety management, Int. J. of Environment and Pollution, Inderscience Enterprise Ltd, 1996, 6 (4 - 6) 537 - 545

(21) Molak, Vlasta. Fundamentals of risk analysis and risk management, Lewis Publishers - CRC Press, 1997

(22) CIRIA (Construction Industry Research and Information Association). Remedial engineering for closed landfill sites, C 557, CIRIA: London, 2001

(23) Pepper, Ian L.; Gerba, Charles P.; Brusseau, Mark L. Pollution science, Academic Press, 1996

(24) DoE (Department of the Environment). This common inheritance: a summary of the white paper on the environment, HMSO, 1990

(25) DoE (Department of the Environment). The technical aspects of controlled waste management - health effects from hazardous waste landfill sites, Report No. CWM/057/92, DoE, 1995

(26) Butt, T. E; Clark, M. and Coulon, F. A review of literature and computer models on exposure assessment, Environmental Technology journal, Vol. 30, No. 14, pp. 1487 - 1501, 2009

(27) EC (European Community), Water Framework Directive, 2000/60/EC, 2000

(28) EC (European Community), Landfill Directive, 99/31/EC, 1999

(29) SI (Statutory Instrument), Landfill (England and Wales) Regulations, SI No. 1559, Crown Copyright, 2002

(30) SI (Statutory Instrument), Landfill (England and Wales) (Amendment) Regulations 2004, SI No. 1375, Crown Copyright, 2004

(31) SI (Statutory Instrument), Waste Management Licensing (Amendment and Related Provisions) Regulations 2005, SI No. 803, 2005 
(32) SI (Statutory Instrument), Landfill (England and Wales) (Amendment) Regulations 2005, SI No. 1640, Crown Copyright, 2005

(33) Scottish Executive; Welsh Assembly Government; Department of the Environment (DoE) Northern Ireland; and Office of the Deputy Prime Minister (ODPM), A Guide to the Strategic Environmental Assessment Directive, ODPM, (September) 2005

(34) EC (European Community) Directive on the Conservation of Natural Habitats and of Wild Fauna and Flora (the Habitats Directive), 92/43/EEC, 1992

(35) Butt, T. E.; Gouda, H. M.; Baloch, M. I.; Paul, P.; Javadi, A. A. and Alam, A., 'Literature Review of Baseline Study for Risk Analysis', Environment International journal, Vol. 63, pp. 149 162,2014

(36) Butt, T. E; Ingles, A. J. D. and Baloch, M. I. A conceptual model outline for integrated exposure assessment, Environmental Progress and Sustainable Energy journal, Vol. 30, No. 4, pp. $696-708,2011$

(37) DEFRA (Department for Environment, Food and Rural Affairs) and the Environment Agency. Model Procedures for the Management of Land Contamination, Contaminated Land Report 11, Environment Agency, Bristol, UK. (September) 2004

(38) Clarke, Robin; Roberts, Ashley; and Conrad, Anne. Chemical prioritisation: ranking chemicals of concern to Scotland's environment, Phase 1: surface waters, SEPA (Scottish Environment Protection Agency), (8 December) 2009

(39) Daginnus, K.; Gottardo, S.; Mostrag-Szlichtyng, A.; Wilkinson, H.; Whitehouse, P.; PayaPérez, A. and Zaldívar, J. M. A modelling approach for the prioritisation of chemicals under the Water Framework Directive, JRC (Joint Research Centre) Scientific and Technical Reports, EUR 24292 EN, European Communities, Italy, 2010

(40) Adidas Group, Framework for the Prioritisation of Hazardous Chemicals - Zero Discharge of Hazardous Chemicals (ZDHC). Joint Roadmap, Version 2 Milestone. 2013

(41). Mendes, M. R.; Aramaki, T and Hanaki, K. Assessment of the environmental impact of management measures for the biodegradable fraction of municipal solid waste in Sau Paulo city, Waste Management Vol. 23, pp. 403 - 409, 2003

(42) EC (European Community) Directive on EIA (Environmental Impact Assessment), which came into effect in July 1988 and has been amended three times, in 1997, in 2003 and in 2009; 85/337/EEC, 1985.

(43) SI (Statutory Instrument), The Town and Country Planning (Environmental Impact Assessment) Regulations 2011, SI No. 1824, Crown Copyright, 2011

(44) Ishizaka, K. and Tanaka, M. Resolving public conflict in site selection process - a risk communication approach, Waste Management, Vol. 23, pp. 385 - 396, 2003 
Figure 1: The Conceptual Holistic Framework of Risk Assessment and Management - Shaded boxes are parts of RA (Concluded, adapted and further developed from $11,16,22,24,25,35$ )

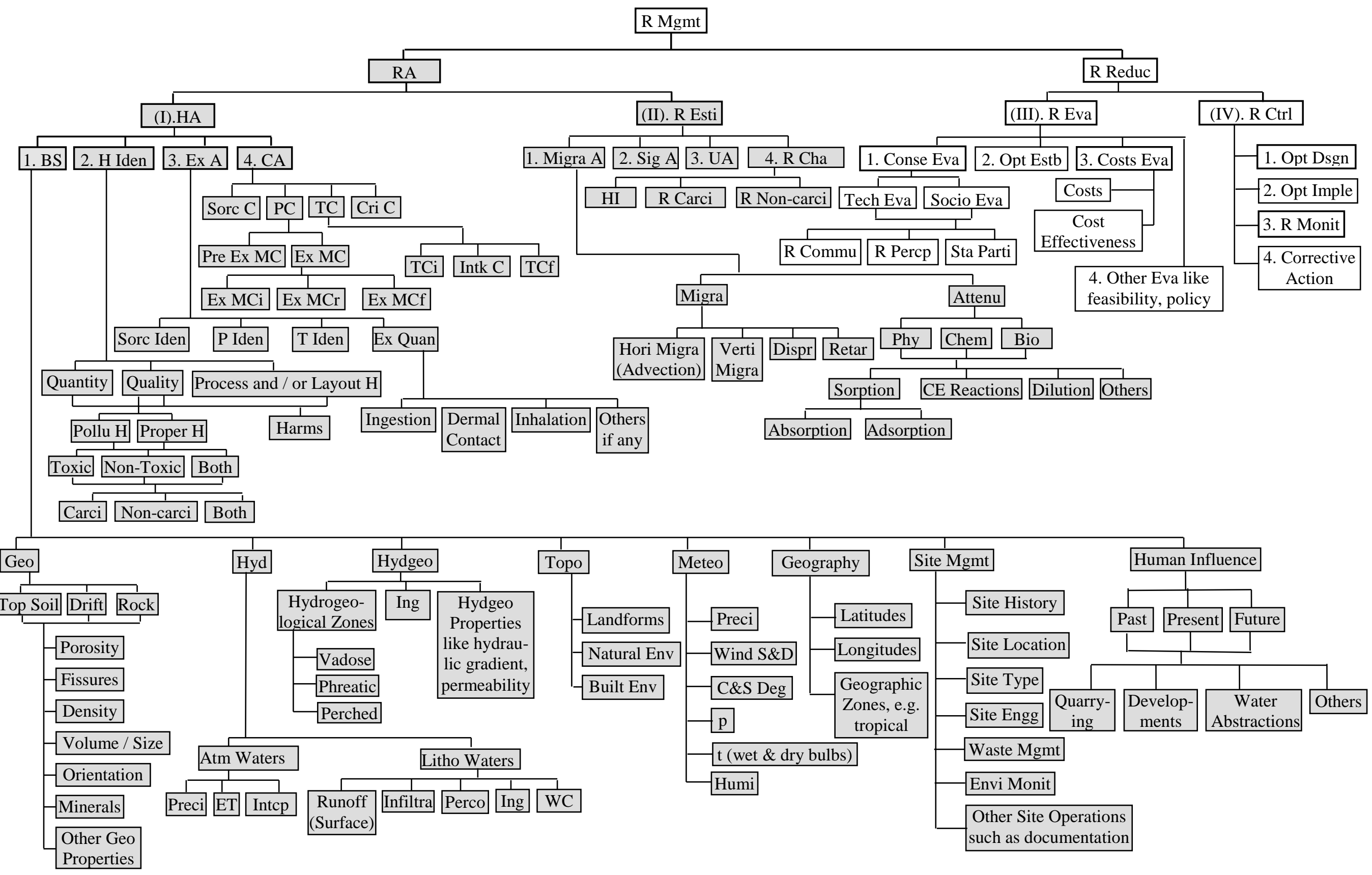


Notation:

\begin{tabular}{|c|c|c|c|}
\hline A & Assessment & $\mathrm{MC}$ & Medium Concentration \\
\hline Atm & Atmosphere or Atmospheric & Meteo & Meteorology / Climate \\
\hline Atm Waters & Atmospheric Waters & Migra A & Migration Assessment (of pollutants) \\
\hline Attenu & Attenuation & Monit & Monitoring or Monitor \\
\hline $\mathrm{B}$ & Baseline / preliminary & Natural Env & Natural Environment \\
\hline Bio & Biological & Non-carci & Non-carcinogen(s) / Non-carcinogenic \\
\hline $\mathrm{BS}$ & Baseline Study & Opt & Option(s) \\
\hline Built Env & Built Environment & Opt Dsgn & Options Design \\
\hline $\mathrm{C}$ & Concentration & Opt Estb & Options Establishment \\
\hline C\&S Degree & Degree of Cloudiness and Sunlight & $\mathrm{P}$ & Pathway \\
\hline Carci & Carcinogen(s) / Carcinogenic & $\mathrm{p}$ & Pressure \\
\hline CA & Concentration Assessment & P Iden & Pathway Identification \& Categorisation \\
\hline $\mathrm{CE}$ & Cation Exchange & Parti & Participation or Participate \\
\hline Cha & Characterisation / Characterise & PC & Pathway Concentration \\
\hline Chem & Chemical & Perco & Percolation \\
\hline Ctrl & Control & Perco & Percolation \\
\hline Conta & Contaminants & Phy & Physical \\
\hline Conse & Consequence(s) & Pre Ex MC & Pre Exposure Medium Concentration \\
\hline Conse Eva & Consequence(s) Evaluation & Preci & Precipitation \\
\hline Costs Eva & Costs Evaluation & Proper & Properties \\
\hline Cri & Critical & Quan & Quantification \\
\hline Cri C & Critical Concentration & $\mathrm{R}$ & Risk \\
\hline Dispr & Dispersion & R Cha & Risk Characterisation / Characterise \\
\hline Dil C & Dilution Concentration & R Ctrl & Risk Control \\
\hline Engg & Engineering & R Commu & Risk Communication \\
\hline Env & Environment & R Esti & Risk Estimation \\
\hline Env Monit & Environmental Monitoring & R Eva & Risk Evaluation \\
\hline Estb & Establishment & R Mgmt & Risk Management \\
\hline Esti & Estimation & R Monit & Risk Monitoring \\
\hline ET & Evapo-transpiration & R Precp & Risk Preceptioin \\
\hline Eva & Evaluation(s) & R Reduc & Risk Reduction \\
\hline EWEQ & Existing Waters Existing Qualities & RA & Risk Assessment \\
\hline Ex & Exposure & Retar & Retardation \\
\hline Ex A & Exposure Assessment & Satu Ing & Saturated Ingress/Phreatic or GW Ingress \\
\hline Ex MC & Exposure Medium Concentration & Site Engg & Site Engineering \\
\hline $\mathrm{Ex} \mathrm{MCi}$ & Initial Ex MC & Site Mgmt & Site Management \\
\hline $\mathrm{Ex} \mathrm{MCr}$ & Reaching Ex MC & Socio & Sociological or Sociology \\
\hline Ex MCf & Final Ex MC & Socio Eva & Sociological Evaluation \\
\hline Ex Quan & Exposure Quantification & Sorc & Source \\
\hline Geo & Geology & Sorc $\mathrm{C}$ & Source Concentration \\
\hline GW & Ground Water & Sorc Iden & Source Identification \& Categorisation \\
\hline $\mathrm{H}$ & Hazard & Sta & Stakeholder(s) and public \\
\hline H Iden & Hazard Identification & Sta Parti & Stakeholder(s) \& Public Participation \\
\hline HA & Hazard Assessment & Subsurface WC & Subsurface Water Course(s) \\
\hline HI & Hazard Index or Indices & Surface WC & Surface Water Course(s) \\
\hline Hori & Horizontal Migration & $\mathrm{t}$ & Temperature \\
\hline Humi Migra & Humidity and / or Relative Humidity & $\mathrm{T}$ & Receptor / Target \\
\hline Hyd & Hydrology & T Iden & Target Identification \& Categorisation \\
\hline Hydgeo & Hydrogeology & $\mathrm{TC}$ & Target Concentration \\
\hline Iden & Identification \& Categorisation & $\mathrm{TCi}$ & Initial / Background Target Concentration \\
\hline Infiltra & Infiltration & $\mathrm{TCr}$ & Reaching Target Concentration \\
\hline Ing & Ingress & Tech Eva & Technical Evaluation \\
\hline Intcp & Interception (Loss) & Topo & Topography \\
\hline Inter & Intermediate & $\mathrm{U}$ & Uncertainty or Uncertainties \\
\hline Inter MC & Intermediate Medium Concentration & UA & Uncertainty Assessment \\
\hline Intk & Intake & Unsatu Ing & Unsaturated Ingress/Vadoze Water Ingress \\
\hline Intk C & Intake Concentration & Verti Migra & Vertical Migration \\
\hline Leach & Leachate & $\mathrm{W}$ & Water \\
\hline Litho & Lithosphere or Lithospheric & Waste Mgmt & Waste Management \\
\hline Litho Waters & Lithospheric Waters & WC & Water Course(s) \\
\hline M & Medium or Media & Wind S\&D & Wind Speed and Direction \\
\hline Mgmt & Management & & \\
\hline
\end{tabular}


Figure 2: 'Input' and 'Output' relationships with Risk Assessment

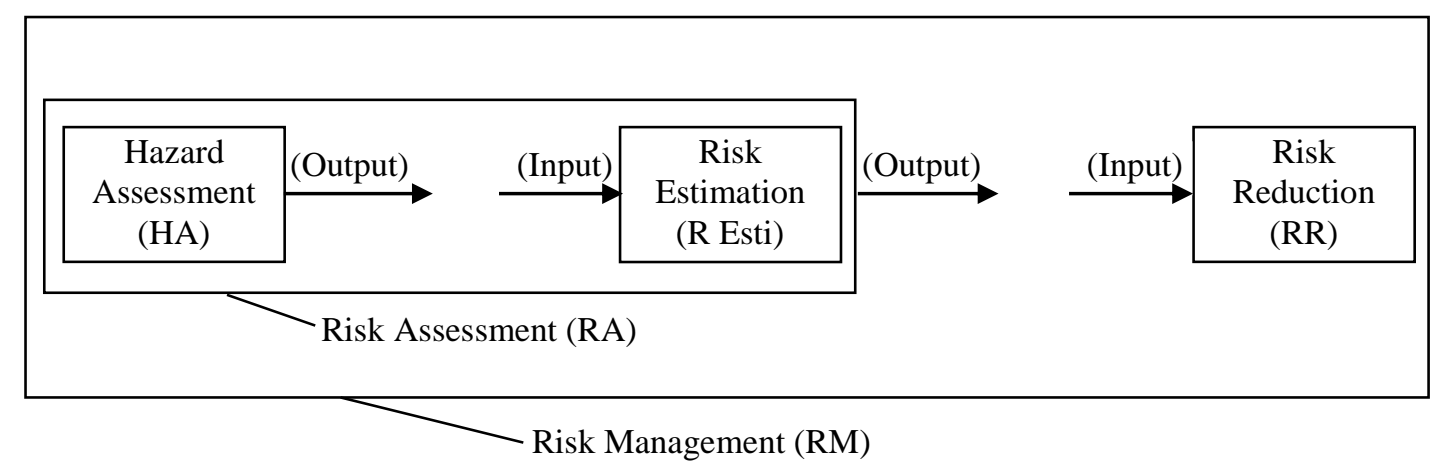

Figure 3: Relationships between Hazard Assessment, Risk Assessment and Risk Management

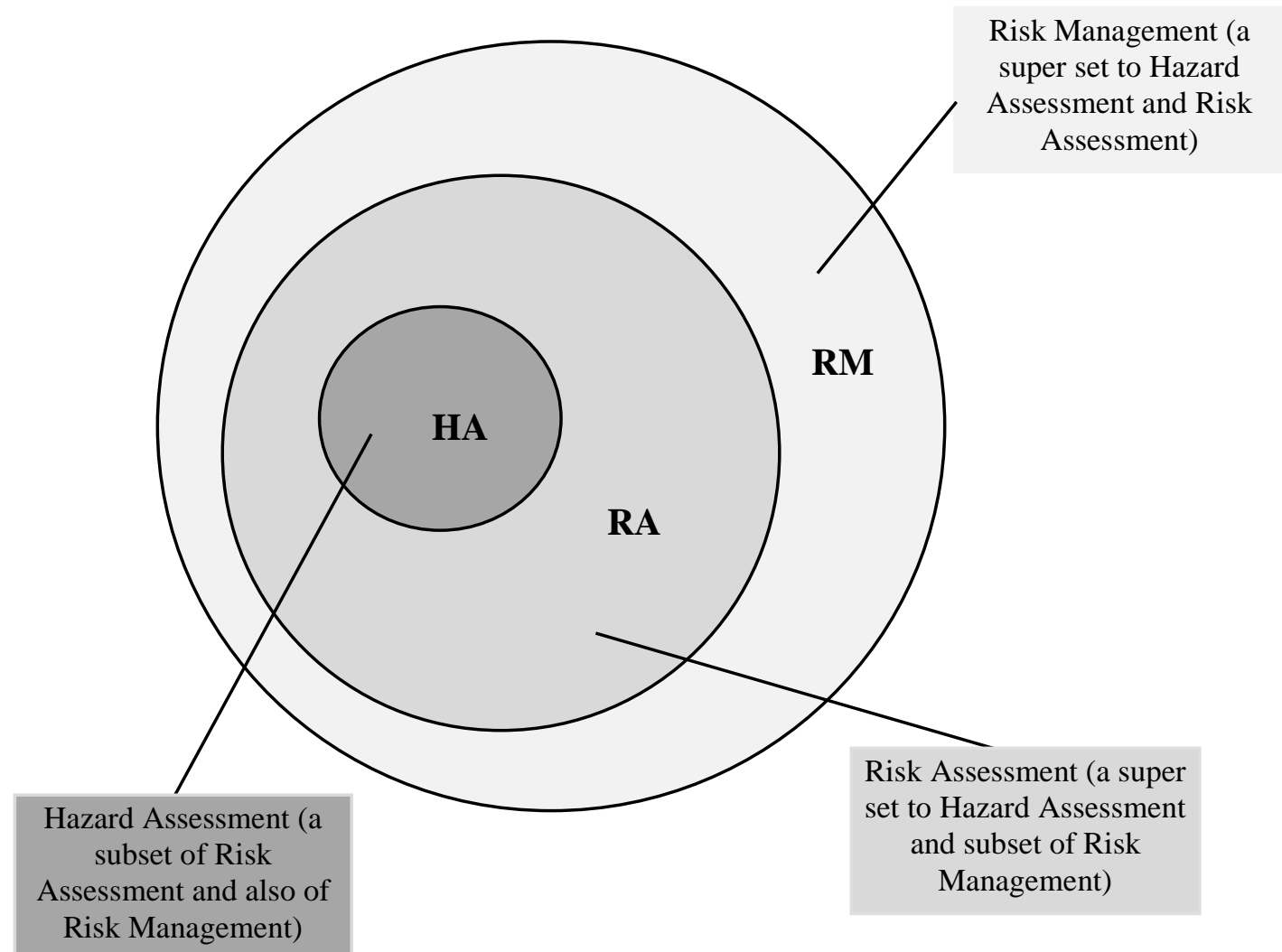

